\title{
Memorias Subalternas sobre la Dictadura Militar en Chile
}

El Caso de la Corriente Liberadora de la Iglesia Católica

Mémoires subalternes sur la dictature militaire au Chili : le cas du courant

libérateur de l'Église catholique

Subaltern Memories on the Militar Dictatorship in Chile: the Case of the Catholic Church's Theology of Liberation

\section{María Angélica Cruz Contreras y Camilo Ramírez}

\section{OpenEdition Journals}

\section{Edición electrónica}

URL: http://journals.openedition.org/assr/26834

DOI: 10.4000 /assr.26834

ISSN: $1777-5825$

\section{Editor}

Éditions de l'EHESS

\section{Edición impresa}

Fecha de publicación: 1 julio 2015

Paginación: 17-35

ISBN: 978-2-7132-2469-0

ISSN: 0335-5985

\section{Referencia electrónica}

María Angélica Cruz Contreras y Camilo Ramírez, « Memorias Subalternas sobre la Dictadura Militar en Chile », Archives de sciences sociales des religions [En línea], 170 | avril-juin 2015, Publicado el 01 junio 2018, consultado el 19 abril 2019. URL : http://journals.openedition.org/assr/26834 ; DOI : 10.4000/assr.26834 


\section{María Angélica Cruz Contreras \\ Camilo Ramírez}

\section{Memorias Subalternas sobre la Dictadura Militar en Chile}

\section{El Caso de la Corriente Liberadora de la Iglesia Católica}

La memoria social es un concepto con el cual interrogarnos sobre cómo van tomando forma los sentidos acerca del pasado en función de los desafíos y problemas del presente, en el acto social de rememorar y olvidar ${ }^{1}$. Se trata de un proceso subjetivo y socialmente construido, donde las memorias no son unívocas sino que, por el contrario, están en permanente disputa (Jelin, 2002). Controversias frente a las que toman tribuna distintos actores que persiguen levantar y legitimar determinadas narrativas, prácticas y marcas cargadas de sentido sobre qué y cómo recordar, qué silenciar y también qué olvidar.

El papel desempeñado por la Iglesia Católica de Chile durante la dictadura militar (1973-1990) suele condensarse en metáforas como la "conciencia deslegitimadora" del régimen o "la voz de los sin voz". Con ellas se ha dado sentido a su labor en defensa de los derechos humanos vulnerados por la persecución política. Sin embargo, ese actuar no fue estático ni uniforme, sino atravesado por distintos liderazgos y grupos que siendo parte de la Iglesia Católica constituyen actores religiosos diversos. Entre ellos, nos interesa uno en particular: la "Corriente Liberadora".

Dicha Corriente, también conocida como "Iglesia popular" o "Iglesia liberadora”, corresponde al sector de la Iglesia Católica, identificada con la "Teología de la Liberación” y que agrupa a miembros del clero y laicos/as vinculados al trabajo con sectores populares (Varios Autores, 2000). Políticamente están más cerca de la izquierda y parte de sus miembros son quienes en los años setenta participaron del movimiento "Cristianos por el Socialismo".

1. Este trabajo está en deuda con las reflexiones colectivas del Proyecto Fondecyt, $n^{\circ} 1110411$ (Cornejo, Reyes y Cruz, 2011). Agradecemos también todo el trabajo de Ignacia Banda y los aportes del Dr Félix Aguirre. 
A partir de la recuperación democrática, la forma en que han operado las memorias sociales del pasado reciente en Chile hace que podamos situar a esta corriente religiosa como un tipo de memoria subalterna, tanto en relación a las memorias más oficiales de carácter nacional, como a aquellas al interior de la Iglesia Católica.

Las investigaciones sobre la memoria social que vienen desarrollándose desde los años 80 (Huyssen, 2002; Jelin, 2002; Traverso, 2000/2007) en el Cono Sur se han enfocado especialmente a los períodos autoritarios marcados por la violación sistemática de los Derechos Humanos desde finales de los años 60' y hasta los 90'. Para el caso de Chile, y de cara a la conmemoración de los 40 años del Golpe de Estado, cobra relevancia adentrarse en la transmisión del pasado a las nuevas generaciones, más aún cuando los “contemporáneos” de la dictadura, dado el paso del tiempo, dejarán de existir como testigos. Con ello se anticipa el "relevo generacional” (Aguilar, 2008), intencionando la "transmisión” de particulares narraciones del pasado (Cornejo, Reyes, Cruz, 2011).

Detrás de esta preocupación lo que está en juego son los silencios y olvidos que también forman parte de la construcción de las memorias sociales (Ricoeur, 2000); algo que no se agota cuando se intenta borrar el pasado (Todorov, 2000), sino también en las relaciones intergeneracionales. Como afirma un reconocido autor, “un pueblo 'olvida' cuando la generación poseedora del pasado no lo transmite a la siguiente, o cuando ésta rechaza lo que recibió o cesa de transmitirlo a su vez, lo que viene a ser lo mismo (...) un pueblo jamás puede 'olvidar' lo que antes no recibió” (Yerushalmi, 1988/1998: 18).

En ese contexto entendemos que en Chile, después de las primeras investigaciones centradas más en las disputas colectivas y en el asentamiento de memorias "emblemáticas" de la Dictadura Militar (Stern, 2000, 2004/2009; Lira y Loveman, 2000, 2002), se ha indagado en los espacios y prácticas sociales que actúan como "vehículos de memoria” (Jelin y Langland, 2003). Se ha abordado, por ejemplo, la enseñanza de la historia reciente (Reyes, 2004) o los lugares de memoria (Piper, Reyes, Escobar y Arteaga, 2008). Tales estudios suelen centrar su atención en la voluntad e intención de quienes van a transmitir, es decir, en los llamados "emprendedores de la memoria" (Jelin, 2002) y en las acciones estratégicas que generan para desarrollar una política activa respecto al sentido del pasado que pretenden legar.

Sin embargo, la transmisión se suele circunscribir a la problemática de los "legados del pasado", en un movimiento unidireccional que va desde la posición generacional protagonista del pasado reciente hacia la posición generacional sucesora (Reyes, 2009a, 2009b). Con ello, se desvaloriza el rol activo que cumplen los "sucesores" y/o "herederos” del pasado, así como el espacio relacional y dialógico que implica el acto de hacer memoria. Si asumimos la memoria como una práctica social, es decir, como proceso intersubjetivo continuo, contingente y contextual, cobra sentido abordar las configuraciones de memorias desde una 
perspectiva dialógica, es decir, considerando que aquello que uno recuerda es una construcción que responde a un "otro". De modo permanente estamos obligados a defender, explicar, justificar y/o silenciar el pasado para sostener una versión que nos dé sentido. Para el caso de la dialogía intergeneracional, es en el espacio relacional entre generaciones donde se producen y reproducen particulares memorias del pasado (Reyes, 2009a, 2009b).

Por otra parte, la memoria siempre es una construcción de sentidos del pasado en función de intereses del presente, y dependerá de las convenciones que circunden en un contexto sociohistórico dado lo que hará memorable o no memorable tales acontecimientos (Halbwachs, 1925/2004; Middleton y Edwards, 1990/1992; Portelli, 2004). Es en este marco que nos interesa la Corriente Liberadora de Iglesia Católica. Si bien Halbwachs (1925/2004) ya situaba a la religión como uno de los marcos principales para construir la memoria social, aquí nos interesa este credo religioso en tanto actor sociopolítico (Veit Strassner, 2006) involucrado en las disputas por hegemonizar las versiones sobre el pasado. Como toda disputa, ésta no opera entre actores iguales sino generalmente marcados por relaciones de poder, con lo que cobra sentido el concepto de memorias subalternas (Traverso, 2000/2007).

Ahora bien, la subalternidad está atravesada por múltiples articulaciones. Nuestro interés aquí es conocer cómo la posición de la Corriente Liberadora se vincula con el actuar de la jerarquía eclesial durante la dictadura y las disputas por las memorias de ese pasado durante los tres primeros gobiernos democráticos (1990-2000), algo que trataremos de esclarecer en la segunda parte. No obstante, nuestro mayor compromiso es comprender los actuales desafíos que enfrenta como Corriente minoritaria, en términos de la transmisión de sus particulares memorias sobre la dictadura a las nuevas generaciones, bajo la sospecha que la falta de recambio generacional y la forma en que se asume la transmisión como un legado, arriesga la posibilidad del olvido de sus experiencias, proyectos e identidades, tema que desarrollamos en la tercera parte. Metodológicamente la primera parte está basada en una investigación que indagó en fuentes documentales, entrevistas a diversos miembros de la Iglesia Católica y etnografías de conmemoraciones de la Corriente Liberadora (Cruz, 2004); la segunda, corresponde al análisis acerca de las continuidades y cambios en el rol de la jerarquía durante el período postdictatorial (Cruz, 2013); mientras que la tercera, se nutre del trabajo de campo de Camilo Ramírez basado en entrevistas ${ }^{2}$ realizadas durante el 2011.

2. Corresponde a su tesis de pregrado en sociología, bajo la dirección de Ma. Angélica Cruz, financiado por el Proyecto Fondecyt, $n^{\circ} 111041$. 


\section{La Corriente Liberadora durante la dictadura militar}

El rol de la Iglesia Católica en el contexto de una sociedad altamente politizada como lo fue Chile durante el gobierno de la Unidad Popular (1970-1973) no estuvo exento de tensiones. Importantes agrupaciones católicas de laicos y de religiosos, contagiados por el entusiasmo doctrinal que provocó la Teología de la Liberación y una creciente comunión entre marxistas y cristianos, apoyaron el "proceso revolucionario" vivido en el país. Su cara más visible fueron los "Cristianos por el Socialismo". Críticos frente a la renuencia de la jerarquía eclesial a apoyar explícitamente al gobierno de la UP, abogaban por cambios institucionales que dieran mayor poder de decisión a los laicos. Todo esto les valió el inmediato rechazo por parte de los obispos (Amengual, 1974), acusándoles de afectar a la unidad de la iglesia e intentar politizarla a favor de la izquierda (Smith, 1990).

Durante los últimos meses de la UP, los conflictos entre la derecha y el gobierno se agudizaron, tensándose también las relaciones entre la Iglesia y la coalición gobernante. Ello no impidió una fuerte crítica de los obispos hacia las expresiones violentas de la oposición, en una postura a favor de una salida pacífica a la crisis política que se avecinaba (Smith, 1990).

A partir del Golpe de Estado, la jerarquía de la Iglesia transitó entre una inicial legitimación del régimen, acompañada de exhortaciones a la "reconciliación”, hasta la denuncia abierta de la persecución política desatada por el aparato del Estado (Smith, 1990). Para entenderlo, nos centraremos en la postura oficial de la Conferencia Episcopal de Chile (CECH) que marcó las relaciones Iglesia-Estado, comprendidas aquí en dos grandes períodos mediados por una etapa de transición.

El primer periodo va de 1973 a 1976, tiempo durante el cual el país permaneció declarado, por decreto de la Junta Militar, en "estado de guerra”, y se dio la más fuerte y sistemática represión de los partidarios del gobierno derrocado, mientras se consolidaba la figura del general Pinochet como rostro de la Junta y de un grupo de tecnócratas neoliberales de la "Escuela de Chicago" encargado de la reestructuración ideológica del modelo económico.

En este periodo hubo un doble juego entre Iglesia y Estado por ambos lados: La jerarquía eclesial aceptaba las reglas del nuevo gobierno de facto, a la vez que comenzaba su asistencia a las víctimas de la represión, mientras que desde el Estado se buscaba el apoyo de los obispos al tiempo que se reprimía a la Corriente Liberadora.

Así, en la primera declaración de la CECH tras el Golpe, los obispos sostenían haber hecho cuanto estuvo de su parte para "evitar cualquier desenlace violento", agregando: "los miembros de la Junta de Gobierno han sido los primeros en lamentar tal desenlace". La declaración expresaba el dolor por "la sangre 
que ha enrojecido nuestras calles", pidiendo respeto por el presidente derrocado y llamando al reencuentro de los chilenos, calificando a los partidarios de Salvador Allende como los "vencidos" y los "idealistas" (CECH, 1974: 174). Paralelamente, a fines de 1973, el cardenal Silva Henríquez impulsó la creación del Comité Ecuménico de Cooperación para la Paz en Chile (COPACHI), abocado a brindar apoyo legal a los perseguidos políticos, facilitar su salida del país, proveer al extranjero las primeras informaciones reales sobre la represión y desarrollar una serie de programas de apoyo a quienes permanecieron en Chile. Después de su disolución por presiones del general Pinochet, la Iglesia Católica creó la Vicaría de la Solidaridad.

El régimen apeló al anti-marxismo de los obispos para tratar de morigerar su déficit de legitimidad política, en coherencia con la autoimagen de un estamento militar y de una derecha social que se presentaban ante la opinión pública como los últimos baluartes de la civilización católica occidental. Al mismo tiempo, realizó ataques selectivos a miembros del Comité y la Vicaría, reprimiendo particularmente a los integrantes de la Corriente Liberadora. Sacerdotes, religiosas y laicos de esta Corriente fueron asesinados y detenidos desaparecidos, sufrieron la tortura y el exilio (Varios Autores, 2000).

La etapa de transición la fijamos entre 1977 y 1980 , periodo en que el régimen militar implementó un conjunto de medidas económicas de recomposición capitalista, que redujeron el papel del Estado en favor de los agentes económicos privados. Este proceso implicó un momento de recuperación económica que benefició sólo a una parte de la población, en detrimento de los sectores más pobres. En 1977 los obispos emiten el documento "Nuestra Convivencia Nacional" (CECH, 1982: 169-170) con el que abordan abiertamente los problemas que aquejan a la nación (detenidos-desaparecidos, crisis económica y falta de libertades). Sin embargo lo hacen en un tono de exhortación más que de crítica, viendo aún factible una recomposición de las relaciones Iglesia-gobierno. Un año después, el gobierno militar dictó una auto-amnistía, que acogía las denuncias de la Iglesia Católica sobre las violaciones a los derechos humanos, pero que no sólo beneficiaba a los condenados entre 1973 y 1978, sino también a los responsables de los detenidos-desaparecidos. La jerarquía eclesial empieza a perder entonces su ya escasa confianza en el gobierno militar, y declaración tras declaración, las exhortaciones van dando paso a denuncias explícitas de lo que ocurría en el país.

La actitud de la CECH hacia el gobierno cambiaría definitivamente en el documento "Orientaciones Pastorales" para el período 1978-1980, marcado por una abierta crítica moral del régimen y los reiterados desacuerdos del Episcopado con la política económica del gobierno. Hacia 1980, año en que el régimen se institucionaliza mediante una nueva Constitución, la Iglesia ya es percibida nacional e internacionalmente como un actor de la oposición (Lira y Loveman, 2000). 
La tercera etapa cubre toda la década del los 80 ' y se caracteriza por una postura abiertamente crítica. A partir de junio de 1982, Chile se ve afectado por una recesión mundial que provoca un creciente desempleo. El régimen militar debe enfrentar, especialmente durante 1983-1984, la movilización callejera de una ciudadanía que se manifiesta mediante "paros” y "protestas" periódicas. La crisis económica merma las bases del proyecto político de los militares y su intento por construir un nuevo orden social. Se descompone el núcleo dirigente, se fragmenta el bloque de apoyo civil, aumenta la represión y se reactiva la oposición política.

El régimen militar se concentra en estabilizar las transformaciones ya impuestas y en defender el itinerario de la transición fijado por su propia Constitución, mientras agudiza su crítica a la jerarquía eclesial, acusándola de ser parte de una campaña de desprestigio internacional contra Pinochet. Entre 1983 y 1986 miembros del clero fueron nuevamente expulsados y detenidos; se prohibió el reingreso al país de uno de los Vicarios de la Solidaridad, y muchos de quienes participaban en las comunidades cristianas de sectores populares, particularmente los que se identificaban con la Corriente Liberadora, fueron arrestados y torturados. Diferentes edificios eclesiales y parroquias fueron allanados, tiroteados, atacados por bombas y/o quemados (Escobar, 1986). Además, el gobierno comienza a tomar medidas "legales" para manifestar su molestia con la Iglesia, incluyendo la censura de varios medios de comunicación católicos.

En 1983 la Asamblea Plenaria de la CECH suscribió la excomunión de los torturadores, demandando el fin de esta práctica. Los documentos oficiales de la jerarquía durante estos años no sólo denunciaron la represión política sino que elaboraron una crítica global al modelo de sociedad que el régimen estaba implantando, particularmente los efectos de las políticas neoliberales. Ni el retiro por edad del cardenal Silva Henríquez, en 1983, ni el nombramiento como sustituto del obispo conservador Francisco Fresno -quien inicialmente apoyó al gobierno militar- modificaron un ápice el activismo pro derechos humanos de la Iglesia (Yáñez, 1988).

En 1985, liderado por Fresno, la Iglesia logró traducir sus llamados a la “reconciliación” en el Acuerdo Nacional para la Transición Plena a la Democracia, que logró aglutinar a la oposición moderada y que buscaba una "salida pacífica" de la dictadura que a la postre implicaría aceptar la Constitución de 1980.

La visita del Papa a Chile en 1987, lejos de ser un impulso a la reconciliación, dio visibilidad a diversas protestas y manifestaciones que aprovecharon las misas masivas, siendo duramente reprimidas por las fuerzas policiales (Veit Strassner, 2006; Lira y Loveman, 2000).

En este contexto la Corriente Liberadora tuvo un importante papel en las acciones de defensa de los derechos humanos, vinculándose a los programas 
eclesiales del COPACHI y la Vicaría de la Solidaridad y ejerciendo una significativa influencia en las prácticas de denuncia de la represión política y de la lucha por la recuperación democrática. En los barrios populares fueron activos colaboradores en la organización de estrategias de sobrevivencia, a través de "las ollas comunes", "los comedores infantiles", "los comités de salud", "los comprando juntos", "los comités de derechos humanos”, entre otros (Cruz, 2004).

\section{Los desafíos de la Iglesia Católica durante la consolidación democrática}

En los años noventa la Iglesia Católica inició una etapa de transición, mediante un repliegue del compromiso del Episcopado con una justicia social y penal horadadas por la violación de los derechos humanos durante la dictadura y en favor de opciones más conciliadoras, como la búsqueda de la equidad en el plano social y la reconciliación en el tema de los derechos humanos. Ello no es independiente de la importancia que fueron adquiriendo las concepciones y prácticas religiosas más tradicionales a partir del liderazgo del Papa Juan Pablo II (Cruz, 2004).

Aunque la opinión prevaleciente apunta a que la Iglesia Católica Chilena progresivamente se aparta de los temas socio-políticos una vez recuperada la democracia, lo cierto es que la $\mathrm{CECH}$ siguió emitiendo declaraciones ante las coyunturas políticas importantes. A través de ellas podemos interpretar cómo el Episcopado ha ido participando en las luchas por dar sentido al pasado autoritario.

Entre 1992 y 1997 los pronunciamientos oficiales sobre temas sociopolíticos muestran una significativa ausencia del pasado dictatorial, incluido el rol que tuvo la institución. Durante esta primera etapa, las memorias de la represión transitan como un pesado telón de fondo, donde nombrar "esos años" se vuelve una tarea esquiva. Si el Episcopado tenía que referirse a la dictadura, lo común era hacerlo mediante sobrentendidos y alusiones, lo que se relaciona con la dinámica de silencios que atravesó a gran parte de la sociedad durante los primeros años de la década.

En un segundo momento, entre 1998 y 2000, y en abierto contraste con las declaraciones de la $\mathrm{CECH}$, las memorias de la represión comienzan a circular de forma más expresa y pública, hasta llegar a tomar cuerpo en narrativas "oficiales" acerca del pasado reciente y sobre el propio rol desempeñado por la Iglesia Católica. Tales narrativas compiten con otros esfuerzos más subterráneos dentro de la institución eclesial, que pugnan por dar un sentido diferente, no sólo a lo que ocurrió sino también al modelo de Iglesia que se anhela para la democracia. 
A finales de los años noventa, coincidiendo con la detención y el procesamiento de Pinochet en Londres, reaparece el tema de las violaciones a los derechos humanos cometidos durante su mandato. Esta coyuntura mostró la fragilidad de la "reconciliación" que algunos creían lograda. La jerarquía de la Iglesia Católica llegó a emitir siete documentos sobre el caso (Cruz, 2004), reconociendo que el tema "derechos humanos" parecía revestido de una "capa protectora" que no permitía cerrar la "herida", lo que implicaba una evaluación crítica respecto a cómo se procesó el pasado autoritario después de lograda la democracia.

En este contexto, observamos tres escenarios donde las memorias sociales de la dictadura se relacionan con diferentes formas de continuidad y cambio en el rol de la Iglesia Católica:

Participación de la Iglesia Católica en las políticas de memoria sobre verdad y reparación: La Iglesia Católica se hizo parte de una serie de medidas gubernamentales en nombre de la "reconciliación nacional" y de las demandas de verdad y reparación, que corresponden a políticas públicas de memoria. Apoyó la conformación de la Comisión Retting ${ }^{3}$, legitimó la Mesa de Diálogo ${ }^{4}$ y autorizó que la Comisión Valech ${ }^{5}$ fuera presidida por un ex Vicario de la Solidaridad. En todos estos casos su participación opera como una suerte de capital moral: la Iglesia puede apoyar o ser garante en el compromiso con la verdad frente a los crímenes de lesa humanidad, lo cual supone una cierta continuidad con su rol de defensa de los derechos humanos.

Redefiniendo las alianzas: A pesar de que la derecha chilena es mayoritariamente católica, durante la dictadura militar el Episcopado pareció distante de las fuerzas políticas conservadoras, por el apoyo que éstas brindaron al gobierno autoritario. Junto con eso, a mediados de los años 80', Monseñor Fresno inició

3. La Comisión de Verdad y Reconciliación fue creada en 1990 por el Presidente Aylwin para elaborar el "Informe Rettig" que recoge las violaciones a los derechos humanos cometidas durante la dictadura, restringidas a los casos de ciudadanos detenidos-desaparecidos, los ejecutados, los secuestros y los atentados contra la vida promovidos por motivos políticos (Cruz, 2002).

4. A consecuencia de la detención Pinochet en Londres, el gobierno chileno convocó a una Mesa de Diálogo (agosto de 1999) para lograr que las Fuerzas Armadas entregaran la información sobre el destino y paradero de los detenidos-desaparecidos. En la Mesa participaron representantes de las Fuerzas Armadas, diferentes Iglesias, abogados de derechos humanos, historiadores y personajes públicos del ámbito de la cultura. Tras meses de trabajo, la Mesa emitió una "Declaración sobre los Derechos Humanos" en la que los militares se comprometían a elaborar un informe sobre el destino y paradero de los detenidos-desaparecidos y donde se reconocía implícitamente que se habían cometido violaciones a los derechos humanos durante el régimen militar.

5. La Comisión Valech fue creada el 26 de septiembre del 2003 por el Presidente Lagos para elaborar otro informe oficial que esta vez reconociera a las víctimas de la dictadura que habían sufrido la privación de su libertad y la tortura, y permitiera gestionar algunas medidas de reparación. 
una serie de actuaciones tendientes a facilitar la rearticulación de los partidos políticos de centro izquierda que se oponían a Pinochet, lo que derivó en la Concertación de Partidos que gobernó tras la caída de la dictadura. A partir de la recuperación democrática, la jerarquía eclesial redefinirá sus alianzas acercándose cada vez más a los partidos de derecha, con el propósito de oponerse a los proyectos gubernamentales que amenazaban su postura en materia de moral sexual y familiar (Veit Strassner, 2006). Un ícono de este pacto fue la reiterada oposición al proyecto de divorcio vincular iniciado en 1995 y cuya ley fue promulgada en el 2004. Otros casos han sido los proyectos que regulan los derechos sexuales y reproductivos, como el acceso universal al método anticonceptivo de emergencia, el aborto terapéutico, los programas de educación sexual en los colegios o las uniones entre parejas del mismo sexo. Frente a los intentos por transformar estos derechos en proyectos de ley, el episcopado ha apelado al Dios de la Vida para oponerse, consigna emblemática de la defensa de los derechos humanos durante la dictadura. Con ello se evidencia cómo los sentidos que se construyen sobre el pasado no se articulan vacíos de objetivos políticos, sino en función de los objetivos y proyectos del presente.

De la lucha contra la violación a los derechos humanos al combate contra la pobreza: En 1992 la jerarquía eclesial cerró la Vicaría de la Solidaridad. En los actos y declaraciones que rodearon este cierre, las autoridades eclesiásticas buscaron reinscribir la "solidaridad" de la Iglesia Católica dentro de un marco menos politizado que el que enfrentó durante la dictadura. La pregunta central apunta a cuál era el rol que le cabía a la Iglesia Católica en democracia, tratando de vincular sus opciones del presente como una continuidad con su misión en el pasado. En efecto, aún cuando se trataba de objetivos distintos, el Episcopado fundió el cierre de la Vicaría de la Solidaridad con la creación de la Vicaría de Pastoral Social como su sucesora, destinada a abordar el tema de la pobreza. Así, señalaron los obispos, se trataba del fin de la Vicaría, pero no de la "solidaridad", en un cambio de giro que redefinía la "solidaridad" con las víctimas de la represión a aquélla con "los pobres", objetivo más neutral capaz de congregar a todas las fuerzas políticas.

En este contexto, la Iglesia Católica enfrenta sus propios desafíos hacia el interior de la institución. Aquí es donde se ponen en juego de manera más evidente las tensiones que suponen los procesos de transmisión del pasado. Así, observamos que en los años 90' se pasa de una sola memoria pública, que al principio de la década se encapsulaba en una figura más bien aséptica políticamente, a una mayor visibilidad de las diferentes tensiones entre metáforas que, aún conviviendo con la anterior, son más arriesgadas en su capacidad para permitir el compromiso político que atraviesa la Iglesia. El cierre de la Vicaría de la Solidaridad y los funerales del Cardenal Silva Henríquez visibilizan tales cambios. 
La institución condensa la labor de la Vicaría en dictadura con la parábola del "Buen Samaritano" sobre la compasión y el amor al prójimo sin distinciones, pero tiene una consecuencia importante: despolitiza la relación que hubo entre víctimas y victimarios. La represión política no fue un hecho delictivo entre ladrones y anónimos asaltados - como en la parábola - sino un hecho político de represión sistemática del Estado. Aún más, la Iglesia no solidarizó con un samaritano del todo distinto al perseguido político: entre las filas de la institución había corrientes progresistas que apoyaron al gobierno de Allende y que fueron por ello también reprimidas.

En el ocaso de la década, la muerte del cardenal Silva Henríquez nos permite observar cómo las disputas sobre el rol de la iglesia en dictadura hacen emerger nuevas metáforas. Cuando el cardenal falleció en 1999, se realizaron homenajes de Estado y masivos funerales. En los diferentes actos y declaraciones, la jerarquía eclesial siguió utilizando la figura del "Buen Samaritano" para sintetizar y circunscribir la acción del Cardenal, pero desde la Corriente Liberadora utilizaron otras maneras de simbolizar lo que fue su labor, y, por ende, también la de la Iglesia Católica durante la dictadura: "la voz de los sin voz", "la protección de los perseguidos”, “el albergue de los 'refugiados”, "el evangelio de solidaridad", "el profeta”. De todas ellas, la significación de "profeta” es la más inclusiva de las diferentes obras del prelado, ya que funde el compromiso religioso y político, al tiempo que permite incorporar las dificultades internas y externas por las que atravesaba entonces la Iglesia.

Por otra parte, durante toda la década la Conferencia Episcopal había mantenido un hermético silencio sobre la represión sufrida por los miembros de la propia Iglesia. Ese silencio viene a ser disputado de manera más pública por los sectores vinculados a la Corriente Liberadora, que recuperan la imagen de una iglesia reprimida junto al resto del "pueblo", en un proyecto de memoria que sintetiza el compromiso de los cristianos y no cristianos que lucharon contra la dictadura miliar en la figura de los "Mártires por la Justicia”. Aquí no se habla de víctimas sino de "caídos"; y no son "otros" sino ellos mismos los que sufrieron la represión, por ser "parte del pueblo", a quien se castigaba (Varios Autores, 2000).

Mirado con cierta perspectiva, tanto la forma en que la jerarquía eclesial ha levantado determinadas narrativas sobre lo ocurrido en el pasado, como los silencios sobre éste que son disputados por las memorias más subalternas, nos permiten apreciar que las luchas por las memorias de la represión dentro de la Iglesia se pueden entender analizando la imagen que construye sobre sí misma y cómo articula esa construcción en relación con su base social y sus aliados, particularmente la forma de entender el límite entre religión y política y cuando es legítimo cruzarlo. 


\section{Los Desafíos de la Transmisión desde las Memorias Subalternas}

A principios de 2011 realizamos una serie de entrevistas a miembros de la Corriente Liberadora en Valparaíso, región que había sido un ícono de su desarrollo durante los años 60’ y 70'. Nuestro interés era indagar en cómo podían interpretarse los desafíos de la transmisión generacional de las memorias del pasado reciente cuando se trataba de memorias subalternas.

Uno de los primeros elementos a destacar es que los procesos de rememoración del pasado permiten observar de manera directa las imbricaciones entre las memorias personales y las institucionales. Sabemos que el acto personal de recordar y olvidar está siempre mediado por los marcos de la memoria (Halbwachs, 1925/2004), y que en las memorias personales se cruzan los niveles individuales y sociales (Jelin, 2002); no obstante, cuando se trata de actores religiosos como el que nos ocupa, se hace más evidente la relevancia del nivel institucional como parte de sus biografías. Así, encontramos en todas las narrativas una suerte de doble memoria: el contexto personal y el contexto eclesial. Se trata de actores que se desenvuelven siempre en esa doble dinámica, a lo que se suman otros cruces identitarios, como las posiciones de género o territoriales.

Particularmente entre los miembros del clero (sacerdotes y religiosas), las rememoraciones sobre la experiencia de la dictadura militar conjugan los elementos ideológicos y eclesiales de la TL con los principios eclesiales más generales que los orientaron, sumado al recuerdo del rol de la Iglesia Católica como gran familia que aglutina diferentes hijos/as. Por lo tanto, a pesar de las diferencias y conflictos que la Corriente Liberadora experimentó con la jerarquía eclesial y los sectores más conservadores de la institución, no hay en ella declaraciones de oposición, sino más bien de pertenencia y reconocimiento de la diversidad que la atraviesa. En esa diversidad, esta corriente, que se sabe minoritaria, exacerba la capacidad que tuvo para hacerse notar y "figurar más", reconociéndose como colectivo dentro de la Iglesia Católica, a pesar de las diferencias ideológicas/ teológicas:

la iglesia es una familia demasiado grande (...) por lo que es difícil que sea homogénea, pero afortunadamente los obispos principales de la Conferencia Episcopal de la época eran bastante progresistas... (...) Había obispos muy reaccionarios (...) en Valparaíso, o en Linares, y sacerdotes también muy partidarios del gobierno militar, y había otros muy comprometidos con la liberación, ...mucho...muy comprometidos con la liberación, yo diría que más... o por lo menos figuraban más... (Religioso/ generación protagonista).

Lo anterior no implica una ausencia de voces abiertamente críticas con la jerarquía eclesial, sin embargo ello no rompe el sentido de pertenencia institucional.

...se está descristianizando y se quiere volver ahí, al cristianismo de cuando yo era pequeño, y qué entienden por cristianismo; ¿un luchar como Cristo con su experiencia de luchar con los pobres, o que se cumplan los dogmas? y, sabes es la rigidez de la dogmática que está tan cuadrada, vieras como los obispos se nombran entre ellos, es 
una rueda que no se renueva, y si lo hace es casi por casualidad, es endógena o como se llame (...) las jerarquías están muy fuera de foco, y es muchísima gente que lo dice, y están perjudicando al pobre pueblo, oprimiéndola con morales sexuales (Religioso/ generación protagonista).

Un segundo tema que nos recuerda este tipo de memorias subalternas es que las posiciones dominadas no son nunca completamente horizontales en sus propias dinámicas, ni están al margen de las diversas dominaciones que atraviesan al resto de la sociedad. Las desigualdades de género, como se sabe, son transversales. Si en la represión política durante la dictadura y en las consecuentes formas de resistencia de la violencia de Estado hubo diferencias de género, no es casual que las memorias sociales sobre el período recuerden, olviden y silencien los mandatos de género y/o den cuenta de experiencias genéricas disímiles.

En el caso de la Corriente Liberadora esto es más significativo entre sus miembros religiosos, especialmente al referirse a la resistencia contra la dictadura. Los hombres enfatizaron en sus relatos las formas de protagonismo directas y confrontacionales, poniendo más énfasis en sus capacidades de influencia en la formación social y política de los sectores donde participaban, que en el quehacer eclesial. El protagonismo personal y la lógica heroica marca así sus narrativas:

Había muchas manifestaciones por supuesto. En cierta ocasión me tomaron, yo tenía un Volkswagen para 12 personas (...) yo venía con frecuencia a la casa del clero, a reflexionar, orar, a leer porque en mi barrio era toda una efervescencia, y en cierta ocasión que estaba en XXX, me avisan, me llaman que habían tomado detenido el furgón con varios jóvenes que iban a...porque íbamos a construir un comedor para niños allá en la última población, tuvimos 5 comedores de niños, ...inmediatamente me vine, y claro estaba en la prefectura de la policía, me hice acompañar de una abogada, Laura Soto...bastante conocida, y yo era muy amigo de ella, así que ella me acompañó a la prefectura, llamó, hizo traer a los jóvenes, lo interrogó en presencia del oficial, y pronto salieron en libertad, porque no había méritos, no había motivos suficientes. (Religioso/generación protagonista).

Las religiosas, en cambio, rememoran prácticas en las que tenían un rol orientado a la asistencia y el apoyo a los perseguidos políticos a través de diferentes medios: la ayuda logística y personal para sacar gente del país, el apoyo a los familiares de los detenidos desaparecidos, entre otros. Este actuar se enfoca desde una postura mucho más eclesial que social y política, y supone recordarse a sí mismas desde posiciones menos confrontacionales, centrándose en el cuidado y la reparación ante el dolor, en las heridas dejadas por la dictadura:

(...) en mi caso, como muchas religiosas, nos amisionamos a todo lo que fue la carta del Cardenal Silva Henríquez, de liberar a toda gente que pudiéramos, de toda la gente que estaba recluida poder darle salvoconducto, poderla pasar a un refugio, para luego pasar a una embajada. (...) todo lo que hicimos fue en enlace con la Vicaria de la Solidaridad (...) Yo lo viví con miedo, porque sabías que hasta lo que hablabas (...) la gente llamados "los sapos", que estaban en la catequesis, que por un precio, recuerdo que eran 30.000 pesos, por entrar en una reunión y llevar la información, 
entonces estábamos fichados, sabían quiénes éramos, y sí, dentro del gozo de salvar la vida de los demás, había miedo (Religiosa/generación protagonista).

Esto es parte de una memoria más invisibilizada, cuyos ámbitos de contención afectiva aparecen como lugares menos glamorosos de la resistencia, pero fundamentales en su capacidad de sostenerla. Asimismo, se recuerdan los espacios de conversación femenina desde donde se reflexionaba sobre lo cotidiano y las propias relaciones de género:

...yo participaba en un centro de madres, (...) todas la señoras enseñaban, entonces yo dije que yo sabía hacer unas blonditas (...) Las hermanas se reían de mí porque decían enseñando frivolite estás loca si la gente quiere tejer y coser, pero me aceptaron (...) y conversábamos de la realidad sexual, de la vida de matrimonio, de los adolescentes, de la crianza de los hijos, de la relación entre los vecinos, de lo que significa ser de una clase social, ganarse el pan, en fin se hablaba de todo (Religiosa/ generación protagonista).

En tercer lugar, el elemento más crítico entorno a las memorias sobre la dictadura militar para esta Corriente es precisamente el problema de la transmisión generacional. Desde una perspectiva política, el desafío de todo actor que experimentó directamente un pasado marcado por la adhesión a proyectos sociales transformadores que fueron violentamente reprimidos desde el Estado, es lograr que esa experiencia no caiga en el olvido, la impunidad o la deslegitimación. Para ellos, los principales receptores de este esfuerzo no son tanto sus pares que estuvieron y están en el otro lado -criticando el gobierno de Allende y defendiendo a la dictadura- sino las nuevas generaciones. En este desafío la Corriente Liberadora es compañera de ruta de otros actores subalternos que pugnan por recuperar la memoria, especialmente las organizaciones vinculadas al Movimiento de Defensa de Derechos Humanos. La particularidad de la Corriente Liberadora en este aspecto es que no sólo debe posicionarse ante la sociedad chilena como memoria subalterna del pasado reciente, sino que también al interior de su propia institución, la Iglesia Católica.

Ante este desafío, lo primero a destacar es que en esta corriente prácticamente no hay herederos/as dentro del clero. Esta ausencia de recambio generacional se debe a la renovación por edad de algunos religiosos y las transformaciones en la formación del clero, sumado a los énfasis del Vaticano que ha criticado duramente a la TL y apoyado los movimientos religiosos más conservadores. Todo ello redunda en la posibilidad del olvido de estas experiencias, proyectos e identidades. Ese es el temor de los sobrevivientes...

La tarea es tratar de recuperar esta memoria, tenerla preparada, pero no hay empuje, no hay, es más, tu fíjate, un promedio de edad, y muchos en 10 años no estaremos (Religioso/generación protagonista).

En cambio entre los laicos y laicas si observamos un cierto recambio generacional; y además alianzas con otros jóvenes que sí están dispuestos a conocerlos, 
aunque no necesariamente se identifiquen con sus posiciones teológicas; las prácticas de transmisión entre la generación protagonista y la sucesora operan, no tanto en el terreno religioso, como en el social, político y ciudadano:

(...) tuvimos una jornada en la Universidad Católica, y había más de 200 personas que no los esperábamos, y la mayor parte eran jóvenes menores de 30 años, entonces quiere decir que los jóvenes que nacieron en dictadura están tomando sus responsabilidades sociales y políticas como les corresponde (Laico/generación protagonista).

Están empezando a aparecer colectivos que no necesariamente adscriben a la fe, pero que están insertos dentro de la misma dinámica, aparecen expresiones diferentes hay un tema que tiene que ver hoy día con que la Teología de la Liberación ha abierto o expandido su abanico de expresión, y ya no se habla de LA TEOLOGÍA Sino de Las Teologías, de la teología feminista, que no tiene que ver solo con el rol de la mujer, sino que se está enfrentando con este diálogo con los géneros, y con las expresiones de la sexualidad, tienes expresiones desde el mundo indígena, que ya no estás dialogando solo con el Dios Jesucristo sino que empiezas a integrar estos espacios de las expresiones religiosas originarias, el tiempo de hoy día me parece súper fecundo en cuanto Teología de la Liberación porque es un tiempo de encuentro (Laico/ generación sucesora).

Por último, lo que nos resulta teóricamente más relevante es la forma dialógica que adoptan las posiciones discursivas de la generación protagonista hacia las generaciones sucesoras, en tanto ejemplifica los dilemas de memorias subalternas que encuentran dificultades para abrirse a nuevos sentidos, resignificaciones, impugnaciones, rechazos o reinterpretaciones por parte de quienes no vivieron directamente el pasado traumático. Así, los entrevistados de esta corriente, tienden a entender el proceso de transmisión intergeneracional de un modo más bien lineal, marcado por una direccionalidad desde quienes estuvieron ahi a quienes no, asumiendo que por no haber vivido el contexto directamente no lo conocen. Desde esta lógica la autoridad para tomar la palabra con relación al pasado se funda en la experiencia directa. Esto incluso adopta a ratos un estilo casi confrontacional, especialmente cuando se asume que las generaciones más jóvenes no se interesan por el pasado:

Yo trabajo harto con jóvenes adolescentes, y en algún momento por curiosidad y cuando hay confianza le pregunto: oye qué opinas tu de la dictadura militar, qué opinión tienes tu de Salvador Allende, y me encuentro con un tremendo vacío, como que los jóvenes no saben, o no quieren hablar o no se sienten capacitados para dar una opinión, y da también señal de esta apatía en términos político partidistas y políticos ciudadanos que encontramos hoy día adentro de los chiquillos nacidos dentro de los 90' donde quieren consumir más que ser ciudadanos (Laico/generación sucesora).

Una consecuencia de esto es que, más que abrir un espacio intergeneracional donde protagonistas y sucesores puedan compartir criterios y experiencias, el foco está en "enseñar la vivencia”, sin buscar un proceso de retroalimentación: La mayoría no saben lo que fue aquello, están en la luna. Entonces nosotros tenemos que pasar esa memoria (...) (Mujer/Religiosa/generación protagonista). 
No obstante, la contingencia de los dos últimos años en Chile (2011-2012), cargada por masivas manifestaciones estudiantiles, ha hecho que algunos de los sacerdotes, religiosas y laicos de esta corriente comiencen a mirar a las generaciones más jóvenes como portadores de proyectos sociales transformadores, en vez de meros espectadores apáticos y/o individualistas:

...yo confío en que los jóvenes van descubriendo caminos nuevos, me da la impresión de que no están contentos con este esquema recibido, (...) y eso está muy bien, muy bien, si son católicos, o no son, bueno no importa, lo importante es buscar caminos nuevos, sin fines políticos, sino que para una sociedad más justa, más justa...si yo estoy bien esperanzado en eso... (...) yo estoy seguro que perciben el Chile como un esquema injusto (Religioso/generación protagonista).

Los protagonistas de la Corriente Liberadora se abren poco a poco a considerar a las generaciones sucesoras como un interlocutor válido, capaz de participar del proceso interpretación del pasado, precisamente porque han empezado a establecer los nexos entre la transformación del modelo de desarrollo chileno con consecuencias en el sistema educacional, y las reformas implantadas durante el periodo dictatorial. Se confirma así lo que han mostrado otros estudios en el campo de la memoria: el pasado no es algo que se "trae" al presente, sino que va cambiando contingentemente.

Hemos intentado mostrar cómo la memoria sobre la dictadura militar chilena que ha venido sosteniendo la Corriente Liberadora de la Iglesia Católica Chilena puede ser entendida como un tipo de memoria subalterna, que comienza a gestarse desde sus prácticas de resistencia contra la violencia de Estado, las transformaciones del modelo económico y social que impuso el gobierno de facto y los propios cambios que experimentó la Iglesia Católica.

En alianza con el rol que cumplió la postura oficial de la Iglesia Católica a través de sus obispos $(\mathrm{CECH})$ durante la dictadura militar, de solidaridad con las víctimas de la represión política y deslegitimación del gobierno militar, la Corriente Liberadora tuvo una importante visibilidad social, una vinculación con diversos actores sociopolíticos que pugnaban por la recuperación democrática, y un apoyo intra-eclesial a pesar de los conflictos que habían tensado la unidad de la Iglesia Católica por su compromiso con el Gobierno derrocado. Sin embargo, una vez recuperada la democracia, las memorias sociales que encarnan los principales actores de esta Corriente se replegaron internamente. A pesar de que apostaban por dar un sentido al pasado diferente a la posición oficial de la Iglesia Católica, sólo en ciertas coyunturas intentaron disputar las narrativas oficiales, cargadas con la lógica de la "reconciliación" y del rechazo al conflicto. Tales intentos nunca arriesgaron una crítica pública hacia la jerarquía eclesial. Sus rememoraciones y denuncias de las nuevas formas de opresión circularon, más bien, por los territorios subalternos de esta corriente: barrios emblemáticos, 
centros de formación teológica, conmemoraciones de sacerdotes asesinatos y detenidos desaparecidos durante la dictadura.

Al preguntarnos por cómo están operando las formas de transmisión de las memorias de la dictadura en el contexto actual, podemos concluir que opera una suerte de paradoja. Como mostramos, durante la transición y consolidación democrática, las disputas al interior de la Iglesia Católica sobre las memorias de la dictadura y el papel desempeñado en ella por esta institución, se resumen en la confrontación de modelos Iglesia, particularmente la forma de conjugar el límite entre religión y política. En ese marco podemos entender que el principal desafío de la Corriente Liberadora es defender la forma en que vivieron el mensaje cristiano durante el período autoritario, así como tratar de contrarrestar el embate conservador que experimentó la Iglesia Católica, intentando influir desde su forma de entender el cristianismo como un compromiso por la liberación del pueblo oprimido. Así, el principal espacio de influencia que se pretende es precisamente la Iglesia Católica. Sin embargo, al indagar en sus discursos en el presente nos encontramos con que no hay en las nuevas generaciones de religiosos/ as herederos que se identifiquen con la Corriente Liberadora. Sí constatamos, en cambio, laicos y laicas que han encontrado en otros actores no eclesiales formas en que su experiencia y sus memorias cobran sentido, en relación con la vocación de la Corriente: el compromiso con las luchas sociales de los actores marginados. En otras palabras, hay riesgos de olvido desde las posiciones de subalternidad institucional, pero hay nuevas formas de aprovechar los significados que se otorgan al pasado y su capacidad para nutrir identidades sociales y nuevos proyectos sociopolíticos, en áreas donde otras subalternidades -fuera de la Iglesia- han comenzado a articularse con quienes han nutrido sus sentidos ciudadanos desde sus adhesiones religiosas.

María Angélica CRUZ CONTRERAS

Instituto de Sociología, Fac. Humanidades, Universidad de Valparaíso angecruz@hotmail.com

Camilo RAMÍREZ

Instituto de Sociología, Fac. Humanidades, Universidad de Valparaíso c.ramirez.vasquez@gmail.com

\section{Bibliografía}

Agullar Paloma, 2008, Políticas de la memoria y memorias de la política. El caso español en perspectiva comparada, Madrid, Alianza.

Amengual Ataliva, 1974, "La Jerarquía Católica Chilena y el Proceso Político Chileno 1970-1974”, Serie Documentos de Trabajo, Año 10, nº 6.

Cornejo Marcela, Reyes María José, Cruz María Angélica, 2011, Memorias de la dictadura militar: Voces e imágenes en la dialogía intergeneracional, Proyecto Fondecyt Regular, $\mathrm{n}^{\circ} 1110411$. 
Cruz María Angélica, 2002, "Silencios, contingencias y desafíos: el Archivo de la Vicaría de la Solidaridad en Chile”, en Silva Catela L., Jelin E., Los Archivos de la Represión: Documentos, memoria, y verdad, Madrid, Siglo Veintiuno de España Editores.

-, 2004, Iglesia, Represión y Memoria. El Caso Chileno, Madrid, siglo XXI.

-, 2013, "La Iglesia Católica, la dictadura y los dilemas de la memoria en Chile”, en Núcleo de Estudios Contemporáneos, Historia, Memoria y la Enseñanza de las dictaduras en el siglo XX, vol. 2: Memoria, Ediciones Gertulio Vargas (en prensa).

CECH, 1974, Documentos del Episcopado. Chile 1970-1973, Santiago de Chile, Ediciones Mundo.

-, 1982, Documentos del Episcopado. Chile 1974-1980, Santiago de Chile, Ediciones Mundo.

Escobar Jaime, 1986, Persecución a la Iglesia en Chile, Santiago, Terranova Editores.

Halbwachs Maurice, 2004, Los marcos sociales de la memoria, Barcelona, Anthropos.

HuYsSEn Andreas, 2002, En busca del futuro perdido. Cultura y memoria en tiempos de globalización, México, Fondo de Cultura Económica.

Jelin Elizabeth, 2002, Los Trabajos de la Memoria, Madrid-Buenos Aires, siglo XxI.

Langland Victoria (comps.), 2003, Monumentos, Memoriales y Marcas Territoriales, Madrid-Buenos Aires, siglo XXI.

Lira Elizabeth, Loveman Brian, 2000, Las ardientes cenizas del olvido. Vía chilena de reconciliación política 1832-1994, Santiago de Chile, LOM.

Loveman Brian, LiRa Elizabeth, 2002, El espejismo de la reconciliación política. Chile 1990-2002, Santiago de Chile, LOM.

Middleton David, Edwards Derek, 1992, Memoria compartida. La naturaleza del recuerdo y del olvido, Barcelona, Paidós.

Nora Pierre, 1997, Les lieux de mémoire, Paris, Gallimard.

Piper Isabel, Reyes María José, Escobar Marcia, Arteaga Catalina, 2008, Usos del espacio, identidades sociales y políticas del recuerdo: Análisis psicosocial de lugares de memoria de los conflictos violentos de nuestro pasado reciente, Proyecto Fondecyt $\left(\mathrm{n}^{\mathrm{o}}\right.$ 1070926).

Portelli Alessandro, 2004, La orden ya fue ejecutada: Roma, las Fosas Ardeatinas, la memoria, Buenos Aires, Fondo De Cultura Económica.

Reyes Leonora, 2004, “Actores, Conflicto y Memoria: Reforma Curricular de Historia y Ciencias Sociales en Chile, 1990-2003”, en Jelin E., Lorenz F., Educación y Memoria. La Escuela Elabora el Pasado, Madrid, siglo XXI, p. 65-94.

Reyes María José, 2009a, Política de memoria como producción cotidiana: la despolitización y la privatización del pasado reciente en el Chile actual, tesis doctoral Universidad Autónoma de Barcelona, no publicada.

-, 2009b, "Generaciones de memoria: una dialógica conflictiva”, Revista Praxis, año 11, $\mathrm{n}^{\circ} 15$, p. $77-97$.

Ricoeur Paul, 2000, La memoria, la historia, el olvido, Madrid, Trotta.

Smith Brian, 1990, "The Catholic Church and Politics in Chile", in Keogh D. (éd.), Church and Politics in Latin America, London, MacMillan Press.

STERn Steve, 2000, "De la Memoria Suelta a la Memoria Emblemática: hacia el recordar y el olvidar como proceso histórico (Chile, 1973-1998)", en Garcés M. et al. (comp.), Memoria para un nuevo siglo, Chile miradas a la segunda mitad del siglo XX, Santiago, LOM, p. 11-33. 
-, 2004, Recordando el Chile de Pinochet. En vísperas de Londres 1998, Santiago de Chile, Ediciones Universidad Diego Portales.

Todorov Tzevetan, 2000, Los abusos de la memoria, Barcelona, Paidós.

Traverso Enzo, 2007, El pasado, instrucciones de uso. Historia, memoria, política, Madrid, Marcial Pons.

VeIT Strassndner M., 2006, "La Iglesia chilena desde 1973 a 1993: De buenos samaritanos, antiguos contrahentes y nuevos aliados. Un análisis politológico”, Teología y Vida, vol. XLVII, p. 76-94.

Varios autores, 2000, Crónicas de una Iglesia Liberadora, Santiago, LOM.

Yerushalmi Yosef, 1988, "Reflexiones sobre el olvido", en Yerushalmi Y., Loraux N., Mommsen H., Milner J. C., Vattimo G., Usos del Olvido, Buenos Aires, Nueva Visión, p. 13-26.

\section{Memorias Subalternas sobre la Dictadura Militar en Chile: el Caso de la Corriente Liberadora de la Iglesia Católica}

Al estudiar los procesos de transmisión dialógica de las memorias sobre la dictadura militar chilena y el rol que en ella tuvo la Iglesia Católica, desde la Corriente Liberadora (Teología de la Liberación), en tanto memoria subalterna, podemos concluir que opera una paradoja. El principal desafío de esta Corriente es defender la forma en que vivieron el cristianismo durante la dictadura, tratando de influir a la propia Iglesia Católica tras su progresivo alineamiento con los sectores más conservadores a partir de la recuperación democrática. Sin embargo, dentro del clero no encuentran herederos o cómplices para esta Corriente, con lo cual se arriesga el olvido de sus experiencias. Sin embargo, los laicoslas han encontrado en otros actores no eclesiales formas en que sus memorias transiten, en tanto recurren al sentido último de la Teología de la Liberación: el compromiso con las nuevas luchas sociales de los actores marginados.

Palabras clave: memorias sociales subalternas, transmisión, Iglesia Católica, dictadura militar chilena.

\section{Mémoires subalternes sur la dictature militaire au Chili : le cas du courant libérateur de l'Église catholique}

Au moment d'étudier les processus de transmission dialogique des mémoires sur la dictature militaire chilienne et le rôle qu'a joué l'Église catholique dans cette dictature auprès du courant libérateur (Théologie de la Libération), en tant que mémoire subalterne, nous pouvons conclure que ce rôle relève du paradoxe. Le principal défi de ce courant est de défendre la façon dont ses partisans ont vécu le christianisme pendant la dictature, en essayant d'influencer l'Église catholique après son alignement progressif sur les secteurs les plus conservateurs, une fois la démocratie revenue. Cependant, le clergé ne trouve pas d'héritiers ou de complices de ce courant parmi ses membres, au risque d'oublier ces expériences. Néanmoins, les laïcs ont trouvé chez d'autres acteurs, non ecclésiaux, des formes par lesquelles leurs mémoires transitent, en ceci qu'ils recourent au sens ultime de la Théologie de la Libération: l'engagement dans les nouvelles luttes sociales des acteurs marginalisés. 
Mots-clés : mémoires sociales subalternes, transmission, Église catholique, dictature militaire chilienne.

\section{Subaltern Memories on the Militar Dictatorship in Chile: the Case of the Catholic Church's Theology of Liberation}

After studying the processes of dialogic transmission of the memory of the Chilean military dictatorship and the role of the Catholic Church, from the starting point of the "Corriente Liberadora" (the Theology of Liberation), understood as a subaltern memory, we can conclude that it operates a paradox. The main challenge of this movement lies in its defending the way in which it experienced Christianity during the dictatorship, trying to influence the Catholic Church after its progressive alignment with the more conservative sectors of the military regime after the restoration of democracy. The impossibility of finding, from within the clergy, heirs of this Current today, bares the risk to see these experiences fall into oblivion. In spite of this, lay activists are managing to find within other non-ecclesiastical actors different ways for these memories to circulate, calling towards the main message of the Theology of Liberation: the commitment to a new social fight for the marginalized social actors.

Key words: subaltern social memories, transmission, Catholic Church, Chilean military dictatorship. 
